\title{
Editorial
}

\section{Christopher Drew}

Teesside University, UK

\section{Sue Eccles}

Bournemouth University

\section{Amanda French}

Birmingham City University, UK

\section{Andy Hagyard}

University of Leeds, UK

\section{John Hilsdon}

University of Plymouth, UK

\section{Christina Howell-Richardson}

Birkbeck, University of London, UK

\section{Craig Morley}

University of Chester, UK

\section{Lucy Rai}

Open University, UK

\section{Gita Sedghi}

University of Liverpool, UK

\section{Alicja Syska}

University of Plymouth, UK

The editorial team is delighted to introduce Issue 13 of the Journal of Learning Development in Higher Education. This issue is published at an exciting point in the life of the Journal as we welcome four new editors to the team, Dr Gita Sedghi, based at the University of Liverpool, Dr Craig Morley from the University of Chester, Dr Christopher Drew from Teesside University, and Dr Alicja Syska from the University of Plymouth. Our editorial team shares expertise in Education and Learning Development but also includes a great mix of disciplinary specialisms ranging from History and Social Work to Chemistry. 
The evidence for distinctiveness in Learning Development roles in Higher Education is growing.

This issue includes an opinion piece from Steven Briggs, Co-chair of ALDinHE, in which he describes how the development of a new professional recognition scheme for Learning Developers acknowledges and celebrates the core values of LD. The scheme, which has been developed through extensive consultation with the LD community, is available to practitioners from academic, academic-related and professional backgrounds. Evolving from a pilot in 2017, the scheme has now been launched with two levels of value engagement: Certified Practitioner (CeP) Institutional commitment; and Certified Leading Practitioner (CeLP) Community commitment. Some 50 colleagues attended sessions describing the scheme at the 2018 ALDinHE conference which bodes well for future applications. Briggs calls the scheme 'an exciting milestone' both for recognition of the work of LDs and for the role of the Association in certifying their professional engagement.

Issue 13 offers three papers and two case studies in addition to Steven Briggs's opinion piece. Three of these share a common theme of the significance of disciplinarity in Learning Development. Crisp's paper 'Coaching placements and incidental learning - how reflection and experiential learning can help bridge the industry skills gap' examines the issues related to the delivery and effectiveness of work-based learning (WBL) support and development, learning styles, and occupational competency in sports education. Specifically, the paper examines the experiences of a level five cohort who undertook supported coaching placements as part of their placement module. As in other disciplines, the findings demonstrate that it is not only preferential, from the sports students' perspective, to engage in supported WBL, but that the coaching placements also helped the students meet many of the wider professional sector's identified skills gaps. Following the theme of vocational learning, Cairns, Hervey and Johnson's paper, 'Neither 'bolt-on' nor 'built-in', is an interesting case study exploring the challenges for enablers of sustaining a disciplinary based Learning Development programme taught in partnership by Law lecturers and Learning Development specialists. The authors acknowledge the partnership model does not easily fit within the existing managerial and organisational structures of contemporary HE and their work reflects on the possibilities and benefits of the partnership model for all stakeholders; and specifically students. 
Minogue, Murphy and Salmons's paper 'Embedding Learning Development: A model for collaborative practice' focuses on support for Criminology and Sociology students and explains how they supported Schools across St Mary's University in the UK through embedding activities in which academic skills were tailored to subject specific module content. Their paper presents the results of a study which evaluated an embedded academic skills module in Criminology and Sociology delivered at Level 4 . They argue that embedding study skills within the curriculum in this way has enabled all students to enhance their Learning Development skills as an integral element of their overall learning - but has been particularly beneficial to those from WP backgrounds. Their study suggests that this has led to increased confidence amongst the students, an increased sense of belonging and greater readiness for students to settle into and gain from their academic studies. They conclude that positioning Learning Development as a normal part of student development at St Mary's rather than a remedial provision for failing students has positive benefits for students and engenders greater collaboration between Learning Development and academic staff. The outcome is an 'impact-tested' accredited skills module that can be adapted and used by other Learning Development Teams.

Delderfield and McHattie's case study, 'The person-centred approach in maths skills development: examining a case of good practice', is based on the practice of an experienced advisor working with three maths students. It offers a reflection on the development of students' mathematics skills in Higher Education, which focuses on the interpersonal dynamics that occur during one-to-one (tutorial) sessions. It offers a novel starting point for conceptualising the importance of 'relationship' in maths skills work, drawing on a person centred approach and exploring behaviours and qualities through the lens of Rogerian core conditions. The use of concepts from the world of therapy provides an interesting approach though which to focus on the relationship between adviser and student, proposing conditions for successful one-to-one practice with students. The study suggests that while there is discussion of becoming unconsciously competent, there is little about what follows. The authors suggest that engaging in this study invigorated professional discussions about the nature of the extensive one-to-one work do and why we have our ethos.

Finally, Jones's focus in the final paper, 'An examination of developmental assets and academic performance in higher education sport students' explores the magnitude and direction of the relationship between developmental assets and academic achievement in 
British students using the Developmental Assets Profile (DAP). The author hypothesises that total asset score, individual asset groups and the eight asset subcategories impact positively on academic achievement. Jones provides evidence that developmental assets are positively associated with grade score in university students; however, the size of the relationship is smaller than previously suggested. 